\title{
Fibrous Dysplasia of the Skull Base Presenting Acutely in an Adult
}

\author{
F. Amoozegar, A. Guberman
}

Can. J. Neurol. Sci. 2006; 33: 325-327

Fibrous dysplasia (FD) of the bone is an idiopathic disorder in which bone-forming mesenchyme develops abnormally. Here, we describe an unusual case in an adult, with recurrent acute headache and third nerve palsy due to FD of the skull base and low-grade fibrosarcoma.

A previously healthy 32-year-old female office clerk, presented with an eight day history of acute-onset, severe, right occipital and retro-orbital continuous headache, associated with nausea and vomiting. She had required dimenhydrinate, acetaminophen with $15 \mathrm{mg}$ codeine, and meperidine with only mild relief of the headache. She also described a 5-day history of right eye ptosis which had progressed to eye closure by the time of presentation. She had otherwise been well, with no systemic or constitutional symptoms and no previous history of headaches.

On admission, she had a complete right eye ptosis but pupils were equal and reactive to light and dilated equally in dim light. Corneal reflex on the right was diminished, and she had decreased sensation to touch and pin-prick in the right V1 and V2 distributions. The rest of her neurological examination was normal. Over the next few days in hospital, she developed horizontal diplopia, worse on left gaze, due to mild right medial rectus weakness.

A CT and MRI showed a lesion at the base of the skull invading and occupying most of the sphenoid sinus (Figure 1). A transethmoidal biopsy of the lesion showed fibrous dysplasia of the skull base (Figure 2). Two days after the biopsy, the patient had significant resolution of her diplopia and headache, with residual minimal right eye ptosis, a $0.5 \mathrm{~mm}$ pupillary difference $(\mathrm{R}>\mathrm{L})$, and mildly diminished right corneal reflex. Surgical excision was deemed unnecessary because the patient had improved significantly.

The patient had another episode of acute headache and right ptosis nine months later. The MRI showed no change of the lesion. Symptoms resolved within a few days. A repeat biopsy four months later was interpreted as giant cell tumor. Over the next year, the patient had four further episodes of right retroorbital headache with partial ptosis and diplopia, each lasting one to five days. An MRI showed no growth of the previous lesion, but changes in the signal characteristics.

Due to the recurrent symptoms and need to determine whether the lesion was malignant, the patient underwent a combined craniofacial resection with transbasal craniotomy and lateral rhinotomy. Most of the tumor was excised. Pathology confirmed the initial diagnosis: monostotic fibrous dysplasia of

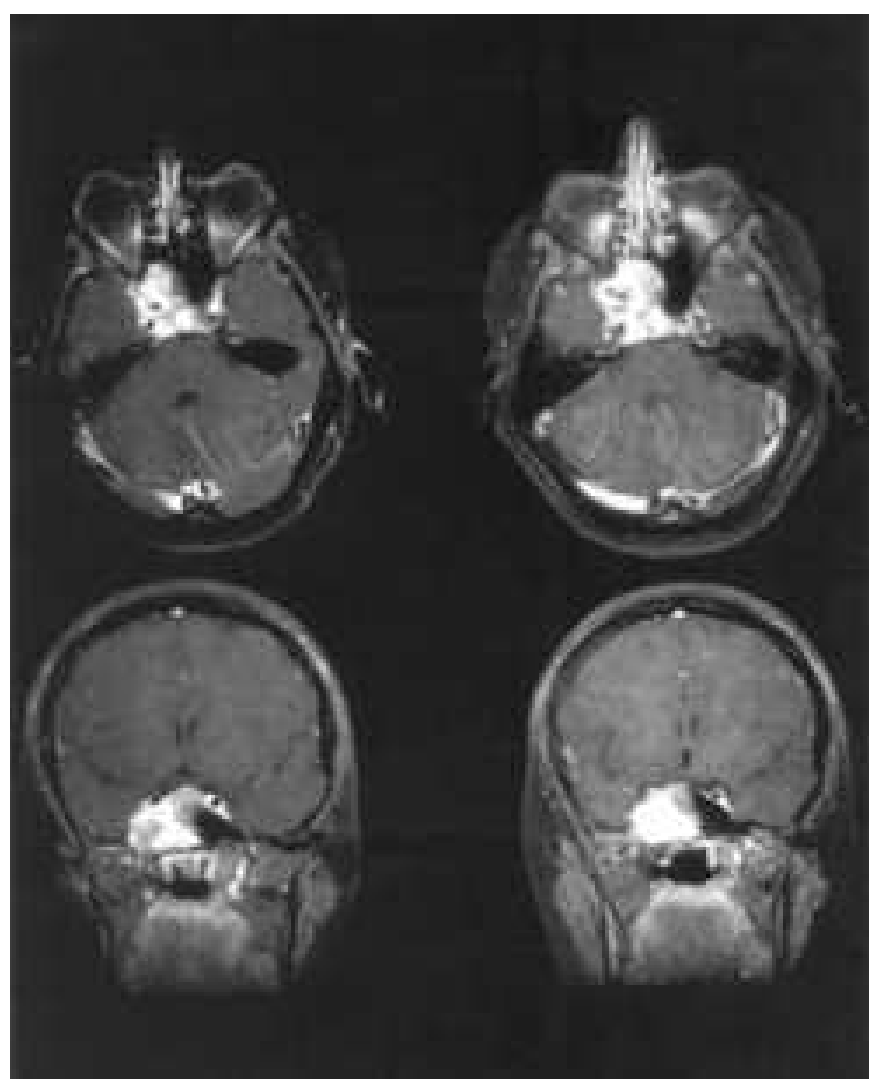

Figure 1. Axial (top) and coronal (bottom) fat suppression T1-weighted MRI images with gadolinium showing an enhancing, extra-axial, spaceoccupying lesion involving the right side of the sphenoid sinus, the right cavernous sinus and the clivus.

From the University of Ottawa, The Ottawa Hospital, Ottawa, ON, Canada Received SePtember 29, 2005. Accepted in Final Form March 21, 2006. Reprint requests to: F. Amoozegar, 144 Costello Avenue, Ottawa, Ontario, K2H 7C5, Canada. 


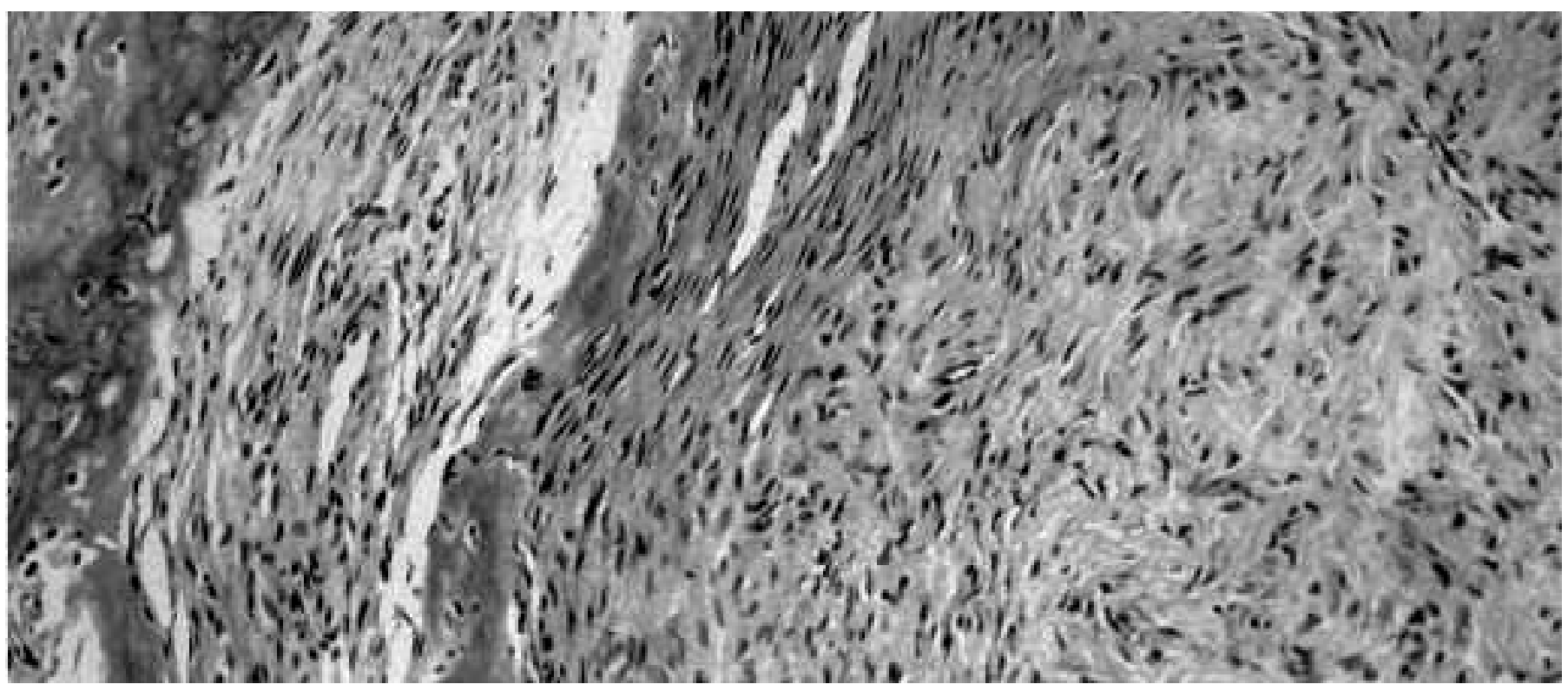

Figure 2. Microscopic image at $800 X$ magnification showing ethmoid mucosa with features of fibrous dysplasia: spindled cells, no mitotic activity, and nuclear atypia. (Courtesy of Dr. D. Wang)

the skull base and low-grade fibrosarcoma. She had several days of radiotherapy with good post-operative recovery and resolution of her headaches and diplopia. Her permanent deficits included minimal ptosis, mild pupillary size difference, and mildly diminished corneal reflex on the right. In addition, she had some loss of smell and taste.

Over the next several years, she continued to remain symptom-free. An MRI in 2002 showed a stable and unchanged appearance of the fibrosarcoma of the sphenoid bone. Ten months later, an MRI showed an increase in the sphenoid mass projecting into the nasal cavity. A repeat biopsy showed pyogenic granuloma, which was managed conservatively. To date, the patient has been well with only minor problems, such as nasal crusting and dryness. She has not had any other episodes of headache, diplopia, or ptosis.

\section{Discussion}

In fibrous dysplasia, as a result of a defect in osteoblastic differentiation and maturation, medullary bone becomes replaced by fibrous tissue. This condition is relatively uncommon and usually sporadic. It is classified into four categories: 1) monostotic (one bone), 2) polyostotic (two or more bones), 3) craniofacial (bones of the cranium and face exclusively), and 4) cherubism (a special autosomal-dominant variant in children). ${ }^{1}$ Although FD usually begins between the ages of three and fifteen years, the monostotic form commonly develops in the second to third decades of life. The vertebrae may become affected, but less commonly than the skull. Spinal involvement, usually in the polyostotic form of the disease, may lead to kyphotic deformity, and in severe cases, spinal cord compression. ${ }^{1}$
About eighty percent of cases involving the skull are monostotic. The frontal, sphenoid, maxillary, and ethmoid bones are most commonly affected. ${ }^{1}$ Frontal bone involvement can produce hypertelorism, cranial asymmetry, and facial deformities. Visual impairment, exophthalmos and even blindness can occur if the orbital and periorbital bones become involved. Lesions of the sphenoid wing and temporal bones may result in vestibular dysfunction, tinnitus and hearing loss. ${ }^{1,2}$ Involvement of the cribiform plate may cause hyposmia or anosmia. ${ }^{1}$ Bone pain and endocrine abnormalities, precocious puberty in girls, hyperthyroidism, hyper-parathyroidism, Cushing syndrome, acromegaly, and diabetes mellitus are other possible manifestations. ${ }^{1}$ Malignant transformation to osteosarcomas or fibro-sarcomas occurs in about $1 \%$ of cases, usually after many years. Features which suggest malignant change include increasing pain and an enlarging soft tissue mass. ${ }^{1}$

Lustig et al found that the ethmoid bones were most commonly involved, followed by the sphenoid, frontal, and maxillary bones. They found that the most common presenting features include atypical facial pain, headache referable to the sinuses, proptosis, diplopia, hearing loss, and facial numbness., ${ }^{2,3}$ Although neurological complications were common, the majority of patients did not present acutely, in contrast to our case. Papadopoulos et $\mathrm{al}^{4}$ reported two cases of craniofacial FD presenting with acute visual loss. One patient had a sphenoid sinus mucocele compressing the optic chiasm, and the second had narrowing of the optic canal from dysplastic bone. In both cases, optic nerve decompression allowed restoration of the vision to normal. Various authors support surgical intervention when vision becomes affected. ${ }^{4-7}$ When patients are asymptomatic, despite optic canal involvement, prophylactic 
decompression of the optic nerve is not advised because of the surgical risk of causing blindness, and the fact that optic canal encasement and visual loss do not necessarily correlate. .,6,7 $^{4}$ Megerian et $\mathrm{al}^{8}$ described ten cases of temporal FD, with nonacute conductive or sensorineural hearing loss. Morrissey et $\mathrm{al}^{9}$ described a case of bilateral temporal FD with unilateral sensorineural hearing loss, facial tingling and twitching. Decompression of the internal auditory canal was performed successfully.

In our case, involvement of cranial nerves III, V1, V2, and VI suggest compromise within the cavernous sinus (Figure 1). We postulate a vascular mechanism to account for the intermittency and recurrence of our patient's symptoms.

Investigations for FD include measurement of alkaline phosphatase, and neuroimaging. Plain x-rays may show single or multiple radiolucent or sclerotic lesions in the skull or facial bones, or can be normal. ${ }^{1}$ A CT classically demonstrates a "groundglass" appearance of the bone, and MRI may add further information. ${ }^{10}$

Currently, there is no consensus regarding the treatment of craniofacial FD, especially in milder cases. ${ }^{1}$ If a lesion is found incidentally on imaging and the patient is asymptomatic, only close follow-up is required. In symptomatic patients with proven FD (e.g. by biopsy), bisphosphonates, such as Pamidronate ${ }^{\circledR}$, can be used. ${ }^{11}$ They reduce symptoms by inhibiting the resorptive activity of osteoclasts and decreasing bone turnover. ${ }^{12}$ Surgical intervention is usually indicated when there is intractable bone pain, severely reduced mobility or functional impairment (from spinal involvement), cosmetic deformity, or local pressure on vital structures. ${ }^{1,4}$ Radiotherapy has been used in some cases of FD, but has not been shown to be effective and may favour malignant transformation. ${ }^{1,4}$

In summary, a wide variety of neurological complications can result from craniofacial FD and cases can rarely present acutely. In addition, symptoms may relapse and remit even with no intervention, as seen in our case. Early diagnosis is important because of the occasional occurrence of malignant transformation. Thus, physicians should closely follow patients and repeat neuroimaging if new symptoms develop or previous ones progress. More than one biopsy may be required to make a definite diagnosis. Although there is no clear consensus on the treatment of asymptomatic or mildly symptomatic patients, most authors agree that surgical intervention is indicated when there are severe or progressive symptoms, intractable pain, cosmetic deformities, or suspicion of malignant transformation.

\section{ACKNOWLEDGEMENTS}

The authors thank Dr. Fred Gentili, the neurosurgeon who performed the skull-base surgery and Dr. D. Wang, the pathologist who helped prepare Figure 2.

\section{REFERENCES}

1. Kumar Neelala Anand, M. Fibrous dysplasia. March 2004. http://www.emedicine.com/radio/topic284.htm

2. Lawson W, Reino AJ. Isolated sphenoid sinus disease: an analysis of 132 cases. Laryngoscope. 1997 Dec; 107(12 Pt 1): 1590-5.

3. Lustig LR, Holliday MJ, McCarthy EF, Nager GT. Fibrous dysplasia involving the skull base and temporal bone. Arch Otolaryngol Head Neck Surg. 2001 Oct; 127(10): 1239-47.

4. Papadopoulos MC, Casey AT, Powell M. Craniofacial fibrous dysplasia complicated by acute, reversible visual loss: report of two cases. Br J Neurosurg. 1998 Apr; 12(2): 159-61.

5. Bocca G, de Vries J, Cruysberg JR, Boers GH, Monnens LA. Optic neuropathy in McCune-Albright syndrome: an indication for aggressive treatment. Acta Paediatr. 1998 May; 87(5): 599-600.

6. Lee JS, FitzGibbon E, Butman JA, Dufresne CR, Kushner H, Wientroub S. et al. Normal vision despite narrowing of the optic canal in fibrous dysplasia. N Engl J Med. 2002 Nov 21; 347(21): 1670-6.

7. Katz BJ, Nerad JA. Ophthalmic manifestations of fibrous dysplasia: a disease of children and adults. Ophthalmology. 1998 Dec; 105(12): 2207-15.

8. Megerian CA, Sofferman RA, McKenna MJ, Eavey RD, Nadol JB Jr. Fibrous dysplasia of the temporal bone: ten new cases demonstrating the spectrum of otologic sequelae. Am J Otol. 1995 Jul; 16(4): 408-19.

9. Morrissey DD, Talbot J, Schleuning AJ. Fibrous dysplasia of the temporal bone: Reversal of sensorineural hearing loss after decompression of the internal auditory canal. Laryngoscope. 1997 Oct; 107(10): 1336-40.

10. Tsai TL, Ho CY, Guo YC, Chen W, Lin CZ. Fibrous dysplasia of the ethmoid sinus. J Chin Med Assoc. 2003 Mar; 66(3): 192.

11. Kos M, Luczak K, Godzinski J, Klempous J. Treatment of monostotic fibrous dysplasia with pamidronate. J Craniomaxillofac Surg. 2004 Feb; 32(1): 10-5.

12. Chapurlat RD, Hugueny P, Delmas PD, Meunier PJ. Treatment of fibrous dysplasia of bone with intravenous pamidronate: longterm effectiveness and evaluation of predictors of response to treatment. Bone. 2004 Jul; 35(1): 235-42.

13. Dumont AS, Boulos PT, Jane JA Jr, Ellegala DB, Newman SA, Jane JA Sr. Craniofacial fibrous dysplasia: with emphasis on visual impairment and current surgical management. Neurosurg. Focus 10 (5): article 6, 2001. 